\title{
Development Features and Fractal Research of fold structure of No.5 Coal Seam in Chenghe-Second Coal Mine
}

\author{
Zhang Zhipei, Cheng $\mathrm{Yi}^{\star}$, and Wang Jia, Wang Xingyu \\ $X i$ an University of Science and Technology,710054 Xi an Shannxi, China
}

\begin{abstract}
According to the collected geological data, this thesis has systematically summarized the development feature of folds of No.5 coal seam in Chenghe-Second coal mine by counting and analyzing the setting of regional geological structure and characteristics of mine geological structure. Based on the above-mentioned study, this thesis has obtained fractal law of fold structure by fractal statistics. The result shows that the folds have a good self-similarity on the plane distribution and obvious fractal characteristics. The result of different mining levels shows that the larger the fractal dimension, the higher the complex degree of fold structures.
\end{abstract}

\section{Introduction}

China is abundant in coal resources with wide distribution, large reserves, whole coal ranges and better development conditions. And coal is the main energy in our country during a long period [1]. Mine geological structure is important production geological conditions, directly affecting mine development and coal seam mining [2]. Therefore, the study of the geological structure of the mine has a universal and practical significance.

Chenghe-Second coal mine has a long history, the production and construction of which have been affected by mine geological structure more and more obviously with the increasing mining intensity. Especially, increasing level of mechanization demands identying the tectonic conditions more exactly. Therefore, it's a prerequisite of improving production efficiency and economic effect of mine to analyse and research folds of Chenghe-Second coal mine and ascertain their development laws and distribution characteristics.

\section{Tectonic Background of Chenghe Mining Area}

According to the viewpoint of plate tectonics, the area locates in the southeast of Ordos block, borders upon Weihe graben system and Qinling folded belt to the south and upon Lvliang folded belt to the east alongside Fenhe graben system and upon the joint of Helanshan folded belt and Liupanshan folded belt. Because of the northsouth compressional stress, the structure of the area has been affected by north Qinling folded belt and Weihe graben and in the mass takes the form of a undulate monocline along almost east-west strike and north dip. Folds mainly develop in the north of Qinling-Huaihe Line and are mostly brachy-axis folds. The dip angle of the area is gentle, which is $10^{\circ}$ commonly.

\section{Fold Features of Chenghe-Second coal mine}

\section{Large and medium-sized folds}

According to exploration and production data, within the mineral rights scope of Chenghe-second coal mine, large and medium-sized folds comparatively develop, including Humazhuang syncline, Xiaoyaoxian anticline, Majiahe anticline, Majiazhuang syncline and Nanyao syncline. Brachyaxis folds mainly develop in southern mine, with the axial length between $100 \mathrm{~m}$ to $400 \mathrm{~m}$ and the amplitude between $10 \mathrm{~m}$ to $20 \mathrm{~m}$ and the dip angles, basically symmetrical, between $10^{\circ}$ to $15^{\circ}$. In comparison with the south, the folds in northern and western mine have longer strike and larger undulation, the axial direction of which is mostly EW, the axial length is $1 \mathrm{~km}$ to $3 \mathrm{~km}$, the width is about $400 \mathrm{~m}$ to $700 \mathrm{~m}$ and the amplitude is $30 \mathrm{~m}$ to $60 \mathrm{~m}$.

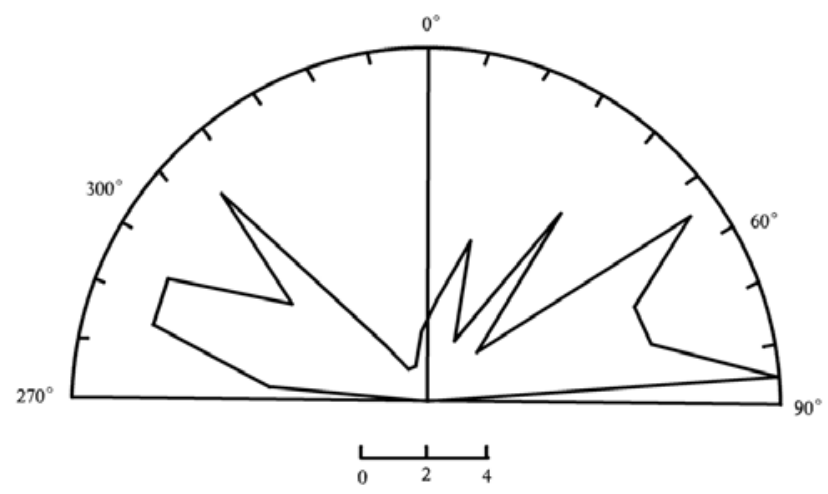

Fig 1.Statistics on axial direction of small-seized folds of No.5 coal seam

\section{Small-sized folds}

In No.5 coal seam of Chenghe-Second coal mine, 98 small-sized folds, including 53 synclines and 45 anticlines, have been discovered.

The axial direction of the small-sized folds possesses a characteristic of irregular distribution. The main axial 
directions include $\mathrm{NEE}\left(\right.$ about $8^{\circ}$ ), NE(about $53^{\circ}$ ), NW(about $315^{\circ}$ ) and NWW(about $290^{\circ}$ )(Fig. 1).

Fractal Research of Fold Structure

Based on the existing data, this thesis researches the fractal features of No.5 coal seam of Chenghe-Second coal mine by Mapgis6.7 and Microsoft Excel.

For the purpose, several grids are been divided, the of which will be reducd with the ratio of 0.5 [3]. As the same time, the total number of grids in which folds develop will be counted.

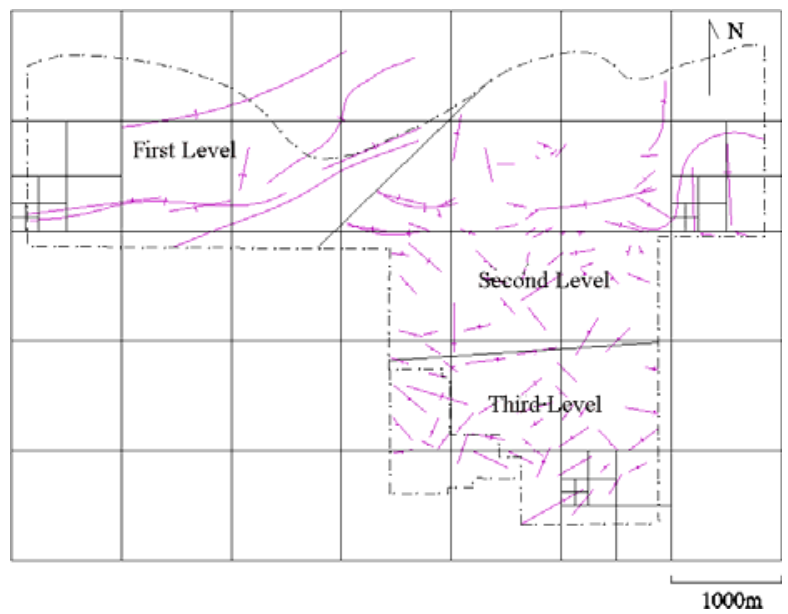

Fig 2. Fold structure fractal diagrams in the study area of No.5 coal seam

If the statistics meet the formula:

$$
N(r)=C r-D .
$$

Where, $r$ is the side length, $\mathrm{N}(r)$ is the total number of grids in which folds develop. If $\mathrm{C}$ is a constant, it can be shown that fold structure has self-similarity within a certain range, and $\mathrm{D}$ is the fractal dimension.

Then, the numerical points, $r$ and $N(r)$, will be calibrated in double logarithmic coordinate system. A fitting line can be obtained from $\operatorname{Ln}(\mathrm{N}(r))$ - $\operatorname{Ln}(r)$ scatter diagram, if fold structure has self-similarity, whose slope is -D and formula is:

$$
\operatorname{Ln}(N(r))=a+(-D) \ln (r) .
$$

Thus, the fractal dimension $D$ and correlation coefficient $R$ can be derived.

Table 1. The horizontal fold grid length $r$ and lattice number $\mathrm{N}$ (r) statistics

\begin{tabular}{|c|c|c|c|c|}
\hline \multirow{2}{*}{ Level } & \multicolumn{4}{|c|}{$N(r)$} \\
\cline { 2 - 5 } & r0=1000m & r1=500m & r2=250m & r3=125m \\
\hline $\begin{array}{c}\text { First } \\
\text { level }\end{array}$ & 5 & 20 & 63 & 203 \\
\hline $\begin{array}{c}\text { Second } \\
\text { level }\end{array}$ & 10 & 28 & 94 & 338 \\
\hline $\begin{array}{c}\text { Third } \\
\text { level }\end{array}$ & 8 & 21 & 61 & 219 \\
\hline
\end{tabular}

Table 2. the $\operatorname{Ln}(\mathrm{N}(\mathrm{r}))$-ln (r) statistical table for each horizontal fold

\begin{tabular}{|c|c|c|c|c|}
\hline \multirow{2}{*}{ Level } & \multicolumn{4}{|c|}{$\ln (\mathrm{N}(\mathrm{r}))$} \\
\cline { 2 - 5 } & $\begin{array}{c}\text { In (r0) } \\
=6.907755\end{array}$ & $\begin{array}{c}\text { In }(\mathrm{r} 1) \\
=6.214608\end{array}$ & $\begin{array}{c}\text { In (r2) } \\
=5.521461\end{array}$ & $\begin{array}{c}\text { In }(\mathrm{r} 3) \\
=4.828314\end{array}$ \\
\hline $\begin{array}{c}\text { First } \\
\text { level }\end{array}$ & 1.609438 & 2.995732 & 4.143135 & 5.313206 \\
\hline $\begin{array}{c}\text { Second } \\
\text { level }\end{array}$ & 2.302585 & 3.332205 & 4.543295 & 5.823046 \\
\hline $\begin{array}{c}\text { Third } \\
\text { level }\end{array}$ & 2.079442 & 3.044522 & 4.110874 & 5.389072 \\
\hline
\end{tabular}

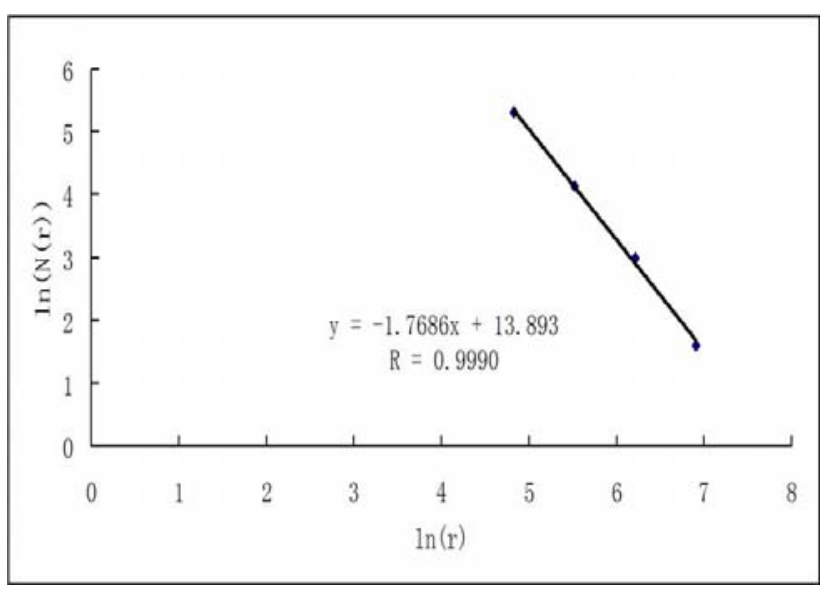

Fig.3 The $\operatorname{Ln}(\mathrm{N}(\mathrm{r}))-\mathrm{Ln}(\mathrm{r})$ fitting line and fractal dimension of fold structure of the first field

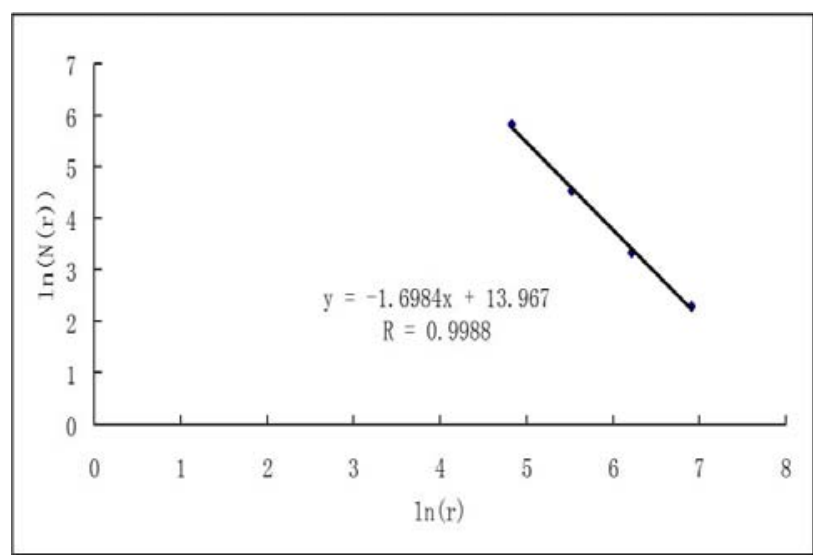

Fig.4 The $\operatorname{Ln}(\mathrm{N}(\mathrm{r}))-\mathrm{Ln}(\mathrm{r})$ fitting line and fractal dimension of fold structure of the second field 


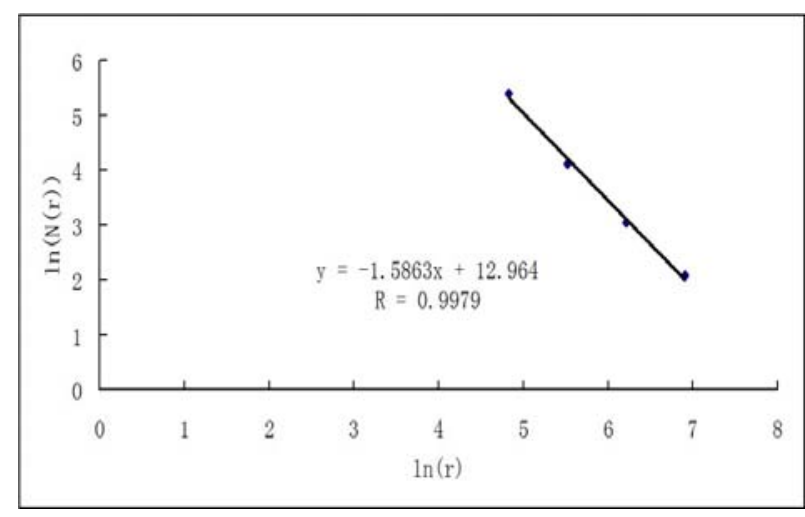

Fig.5 The $\operatorname{Ln}(\mathrm{N}(\mathrm{r}))$-Ln(r) fitting line and fractal dimension of fold structure of the third field

Table 3.The fractal dimension $\mathrm{D}$ and correlation coefficient $\mathrm{R}$ of fold structure of each level

\begin{tabular}{|c|c|c|}
\hline Level & $\begin{array}{c}\text { Fractal dimension } \\
\mathrm{D}\end{array}$ & $\begin{array}{c}\text { Correlation } \\
\text { coefficient R }\end{array}$ \\
\hline First level & 1.7686 & 0.9990 \\
\hline Second level & 1.6984 & 0.9988 \\
\hline Third level & 1.5863 & 0.9979 \\
\hline
\end{tabular}

The correlation coefficient $\mathrm{R}$ of fold structure of each mining level is larger than 0.9979 and the fractal dimension D is 1.7686, 1.6984 and 15863 respectively, namely the fractal dimension of first level is largest, then second level and third level is smallest. It can reflect in the data that complex degree of fold structure of first level is highest, followed by second level and third level is lowest (Table 3).

Table 4. $5 \#$ fold seam grid length $r$ and lattice number $N(r)$ statistics table

\begin{tabular}{|c|c|}
\hline $\mathrm{r}(\mathrm{m})$ & $\mathrm{N}(\mathrm{r})$ \\
\hline 1000 & 22 \\
\hline 500 & 76 \\
\hline 250 & 255 \\
\hline 125 & 886 \\
\hline
\end{tabular}

Table 5. 5\# fold seam grid $\ln (\mathrm{N}(\mathrm{r})$ ) $-\ln (\mathrm{r})$ statistical table

\begin{tabular}{|c|c|}
\hline $\ln (\mathrm{r})$ & $\ln (\mathrm{N}(\mathrm{r}))$ \\
\hline 6.907755 & 3.091042 \\
\hline 6.214608 & 4.330733 \\
\hline 5.521461 & 5.541264 \\
\hline 4.828314 & 6.786717 \\
\hline
\end{tabular}

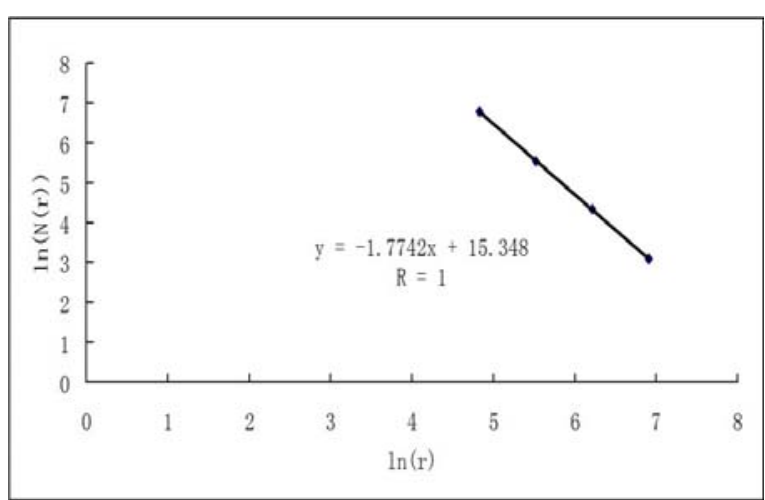

Fig.6 The $\operatorname{Ln}(\mathrm{N}(\mathrm{r}))-\operatorname{Ln}(\mathrm{r})$ fitting line and fractal dimension of fold structure of No.5 coal seam

The result that the fractal dimension $\mathrm{D}$ of fault structure of No.5 coal seam is 1.7742 and the correlation coefficient $\mathrm{R}$ is 1 shows that fold structure of ChengheSecond coal mine has a good self-similarity and meets fractal laws (Fig. 6).

\section{Conclusions}

The following conclusions can be obtained, by researching structure features and fractal theory.

(1) In No.5 coal seam of Chenghe-Second coal mine, 5 large and medium-sized folds have been discovered, including 2 anticlines and 3 synclines, all of the axial direction are mostly WE.

(2) In mined area of No.5 coal seam, 98 small-seized folds have been discovered, including 45 anticlines and 53 synclines. The main axial direction include NEE, NE, NW and NWW.

(3) The fractal dimension D of fold structure of No.5 coal seam is 1.7742 and the correlation coefficient $\mathrm{R}$ is 1 , which shows that fold structure has a good self-similarity and obvious fractal features.

(4) In each level, the fractal dimension D of first level > second level $>$ third level, and the correlation coefficient $\mathrm{R}$ is larger than 0.9979, which shows that the larger the fractal dimension, the higher the complex degree of the structure [4], therefore, the more the influence on safety production.

Acknowledgements

This work was financially supported by Shaanxi Nature Science Fund Project (SJ08-ZT08-3).

\section{References}

[1] Zengxue Li etc, Coal Geology (Geology Press, China 2009)

[2] Zengxue Li etc, Mine geology (Coal Industry Press, China 2009)

[3] Feiyan Zhang, Xiaoshan Chen, Coal Geology of China, Vol.20, No.3, p.16-19 (2008)

[4] Yucheng Xia, Huanren Fan, Mingxing $\mathrm{Hu}$ etc,Journal of Xi'an University of Science \& Technology, Vol.17, No.1, p.22-24 (1997) 